\title{
Education of Hydraulic Engineers
}

\section{Formation des ingenieurs hydrauliciens}

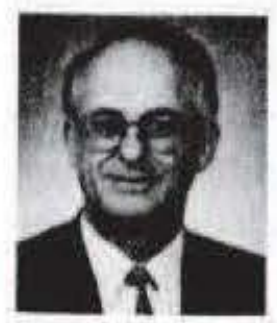

\author{
Prof. Dr. HELMUT KOBUS \\ Institut für Wasserbat \\ Universituät Stuitrgart \\ D-70550 Stuttgart
}

Prof. Dr.-Ing. ERICH PLATE

Inst. fuir Hudrologie

und Wasserwirtschafi

Universiär Karlsnuhe

D-76/28 Karisrulie
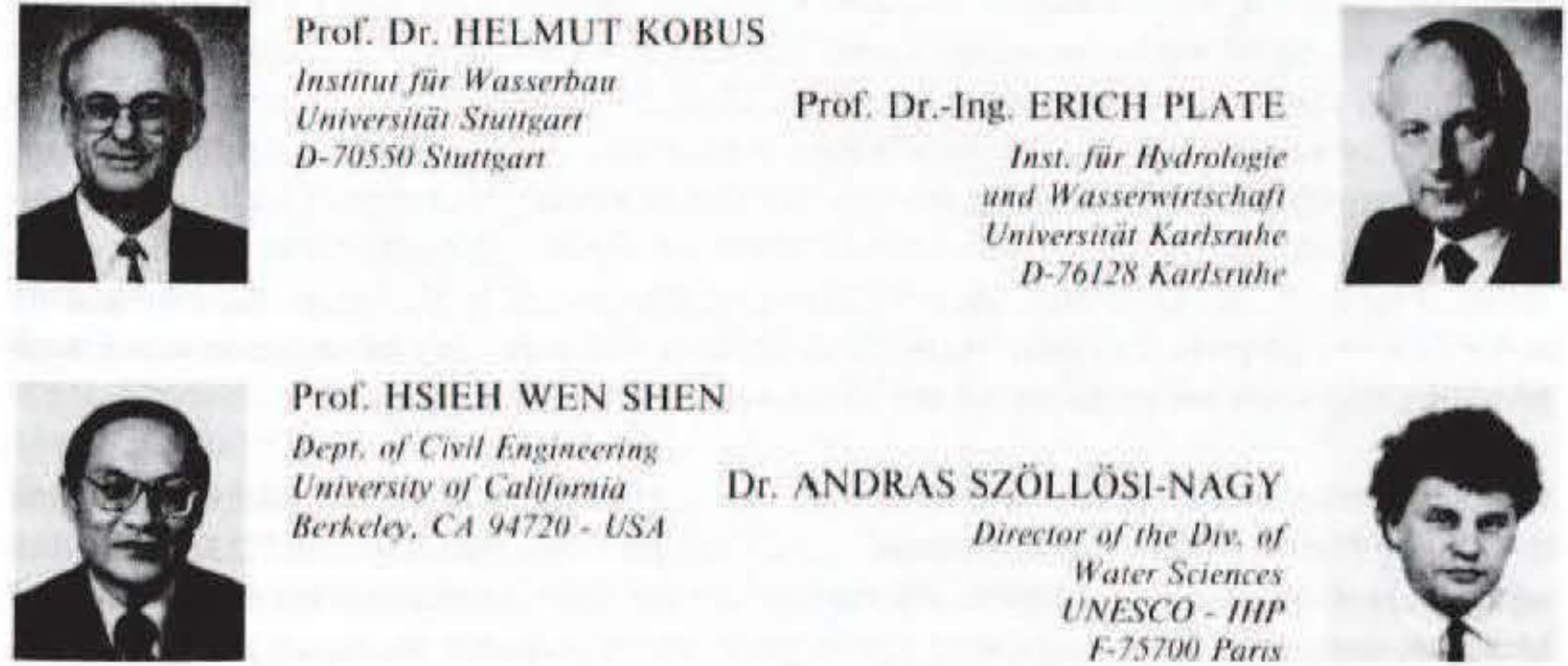

\section{Prof: HSIEH WEN SHEN}

Dept, of Civil Engincering

University of Califunia

Berkeley, CA 94720 - USA

\author{
Dr. ANDRAS SZÖLLÖSI-NAGY \\ Director of the Div. of \\ Water Sciences \\ UNESCO - IIIP \\ F-75700 Paris
}

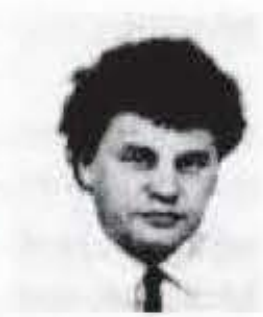

\begin{abstract}
In this report, a joint IAHK and UNESCO panel addresses the current developments in hydraulic engineering and their implications for the education of hydraulic engineers. The framework of underlying basie sciences, geosciences and engineering scienees and the large variety of engineering subjects involved must be seen in the broader context of the natural and social environment. In addition to its classical tasks, hydraulic engineering has evolved to deal with water quality, environmental issues and ecology. and it is further broadened by the new challenges posed by the need for sustamable development and by the threat of global changes. New developments in science and technology and compoter sciences must be reflected both in contents and methods of teaching. Education must also provide engineering skills and procedures as well as professional preparation including the ability to work in interdisciplinary teams. In view of these developments, continuing education will have a major role to play, and large-scale systems and international aspects will be of increasing importance. These developments call for suitable IAHR activities.
\end{abstract}

\section{RÉSUMÉ.}

Dans ce rapport, un groupe de rêllexion commun a PAIRH et I'UNESCO présente lés récents développe: ments en ingénieric hydrauliques et leurs implications pour la formation des ingénieurs hydrauticiens. L'ossature des disciplines fondamentales sous-jacentes, sciences de la terre et sciences de l'ingénierie ainsi qu'une grande variété de sujets d'ingénierie concernés, doivent être considérées dans le contexte le plus étendu de Fenvironnement naturel et social. En plus de ses missions traditionnelles, Fingénierie hydraulique a évolue pour prendre en compte la qualité de l'eau, les contraintes d'environnement et l'écologie, et elle voit son champ encore élargi par les nouveaux défis posés par les besoins du développement et la menace de bouleversements mondiaux. Les nouveaux développements dans les sciences, la technologie et l'informatique doivent être pris en compte à la fois dans le contenu et dans les méthodes de l'enseignement. La formation doit egalement couvtir le savoir-faire en ingènierie de même que la prèparation à ta vie professionnelle qui comprend la faculté de travailler dans des equipes pluridisciplinaires. Dans l'optique de ces développements. la formation permanente aura un rôle majeur a jouer, et les systemes a grande échelle ainsi que les aspects internationaux seront d'une importance croissante. Ces développements demandent une implication adéquate de I'AIRH.

Revision received Open for discussion till October 31. 1994. 


\section{Introduction}

Hydraulic engineering has served mankind throughout the ages both by providing drinking water as well as protective measures against floods and storms. In the course of history, it has made the water resource available for human uses of many kinds.

Management of the world's water is a complex task, and both its scope and its importance continue to grow. As the world's population keeps increasing, the ever growing needs for water have to be met by the limited natural water resources. Thus, the goals of supplying mankind with the water needed while preserving the world's natural resources lead inevitably to conflicts. The increased demands on the fixed supply of water have led to a steady evolution of both the procedures involved in handling water resources and in the science that undergirds it. Even the objectives are evolving as the need to protect the environment, both now and for the future, has enlarged the scope of water projects. The impacts of these changes will inevitably be reflected in the ways hydraulic engineers are prepared for the challenges in the next century.

In view of these developments, the International Association for Hydraulic Research (IAHR) and the United Nations Educational, Scientific and Cultural Organization (UNESCO) decided to assess current developments in hydraulic engineering and their implications for the education of hydraulic engineers. They established a joint panel which prepared the report presented here.

\section{From early times towards a sustainable future ${ }^{1}$}

\subsection{Evolution of hydraulic engineering}

Since the beginning of civilization when man settled down in the fertile valleys of large rivers, like the Nile in North Africa and the Yangtse in China, the development of water resources has been one of the major tasks of mankind. People have always depended on the development of their water resources for survival in environments that often experience droughts and floods. Adjustment to the vagaries of the water flows required major efforts and ingenious technical solutions, mostly for irrigation and flood protection. Over centuries of trying, and sometimes failing, engineers sharpened their skills. Hydraulic engineering, in its empirically developed form, is among the oldest professions, one on which the well being of many civilizations has depended through the centuries, from antiquity to the engineering works of today.

In the course of time, mankind has not only diverted and used the waters of the world for its purposes, but by forcing nature into its service has turned deserts into fertile agricultural areas.

\footnotetext{
'adapted from ref. [3]
} 
Recognition of the threats to mankind and to the world has led to attempts to set a new course for development. Perhaps the most fruitful statement for such a course is proclaimed in the report "Our common future" produced by the World Commission on Environment and Development [1]. Known as the Brundtland Commission report, it reviews the present pattern of development and economic growth and sets a framework for action by promoting the all-encompassing concept of sustainable development. It showed that social and economic development need not be in conflict with the protection of the environment, provided that humanity adjusts to the special requirements imposed by sustainable development. It has also given the world a direction for development, a road to an acceptable future, and it has resonated on all political levels. It ultimately led to the United Nations Conference on Environment and Development (UNCED) held in Rio de Janeiro in June 1992.

Sound and effective management of water resources has a key function in sustainable development. The Brundtland Commission did not recognize specifically the importance of water as lifeblood, as a factor that places limits on development. However, this important omission was remedied through actions at other meetings on the way to Rio. The details of how these actions can be performed in the real world are left open; they must be supported by full acceptance at all political levels, and by contributions from many professions and sciences.

Water engineers and scientists are confronted with the challenge of sustainable development, and they must translate it into concepts that are useful in maintaining and managing our water resources and in designing and operating the projects involved. These tasks require the amalgamation of traditional engineering with environmental thinking in ways that are partly traditional and partly new. The methodology may not change substantively, but its objectives and underlying philosophy will differ from traditional practices. Educators are challenged to present their subjects with full regard for their environmental settings and to make their students aware of environmental consequences. The complexities are likely to require an approach that is systems oriented. Hydraulic engineers should as always serve the needs of their clients, but these needs must come to include an integration of their work into the natural ecosystem, and a point of view that successfully incorporates a long term future.

\subsection{Impacts on engineering eduction}

Hydraulic engineering at mid-century was a well established branch of Civil Engineering whose practitioners had designed and built some of the largest structures ever constructed; the Hoover dam and the Grand Coulee dam in the US, and the Dnepropetrovsk Hydropower project in the former USSR are examples. Its foundations were laid by distinguished scientists and engineers who evolved a body of design knowledge that fit their needs. Underlying concepts came from the theory of incompressible, frictionless fluids, and these were extended through experiment and observations of existing structures to include energy losses and effects of non-uniformity of flow by means of empirical coefficients. The collective experience of engineers and laboratory research had been ordered into excellent textbooks. Educators everywhere were able to provide their students with a coherent and comprehensive body of knowledge, that was sufficient for almost all design problems. The state of the art of hydraulic engineering at mid-century is well represented by the great handbooks that came out during that decade: Davis' "Handbook of Applied Hydraulics" [2] in the USA, and Schleicher "Handbuch des Bauingenieurwesens" [10] in Germany, to name only two. 
But by that time theoretical foundations had already been laid for a more enlightened hydraulics that was being integrated into most curricula, an approach based on fluid mechanics. Processes which in the past had been characterized by experimental coefficients were also investigated analytically. The foremost promoter of this period of change was Hunter Rouse and the widespread book "Engineering Hydraulics" [9] that he planned and edited. It stimulated a vigorous development of fundamental research in hydraulics, and the results were made available to an ever more scientific community, particularly through the efforts of the International Association of Hydraulic Research and the American Society of Civil Engineers.

Fundamental research received an enormous boost from the evolution of the digital computer in the sixties and seventies. Initially its application concentrated on numerical modeling of hydraulic processes, like unsteady flow in open channels and groundwater flows. But soon its potential for data gathering and analysis was recognized, and by 1970 it had also altered the way research was done. It continues to exert a strong influence on all aspects of hydraulics, and its applications range from simulation models of complex turbulent flow fields to storage and retrieval of vast amounts of detailed information. It has also altered drastically the processes of design and experimentation. And the computer is at the bottom of another significant advance in the field of hydraulic engineering: the recognition and explicit handling of random processes. The hydraulic engineer through the nature of hydrologic and other natural information saw how his structures interacted with natural processes and that these could only be handled by statistical means.

The sixties were a time of awakening concerns about the environmental and social consequences of technological development. Hydraulic engineers had to learn to develop and work within much broader terms of reference. Concern for the environment, for the effects of cooling water and sewage on rivers and lakes and for the consequences of structures on flora and fauna broadened the scope of hydraulics and stimulated a vigorous research activity. The public as well as the hydraulic engineers are increasingly involved in a variety of tasks that this new awareness has brought about. Now the still more recent concept of sustainability is further altering the scope of action.

The logical response by science to this increased awareness of the interacting relation between engineering and economics, on the one hand, and conflicting societal needs and goals, on the other, is the emergence of water resources planning as a formal discipline. Water resources planning in this sense includes the hydraulic project as part of a larger planning process in which it occupies an important sector [7]. An early and remarkable practical example of this approach has been set by the successful system planning of the Tennessee Valley Authority (TVA) in the thirties and forties. Water resources planning has been used primarily in studies involving shortages of water, and in planning huge, internationally financed water resources projects in developing countries. The need for sharing experiences gained in developing such projects has been recognized, and curricula for hydraulic engineering should reflect this development. Special skills are needed for planning, constructing, operating, maintaining and managing these larger water resources systems.

Hydraulic engineers must be able to describe and quantify the physical processes in the environment, with due consideration of chemical or biological effects. Their designs should involve not only the design conditions, such as maximum load and the design flood, but also the performance under a variety of naturally occurring conditions. They must incorporate the stochastic time 
series of the processes that cause the loads, and this leads in a natural way to the requirement that they involve hydrology and hydraulics as interactive components of the design process. An assessment of the environmental impact requires a wealth of information from other fields of science, and hence engineers must interact as part of teams that include natural scientists, sociologists and decision makers. This change in objective and in approach must be reflected by the way in which the subject is taught to the engineers of the future. Hence, engineering educators are called upon to review and broaden parts of their programs of study.

As a result of the foregoing evolution, hydraulic engineering as we see it today represents a technical-scientific field that encompasses many basic and applied branches of science: it can be roughly structured according to Fig. 1. Education in hydraulic engineering must rely on a number of basic sciences and geosciences and has its essential scientific base in the underlying engineering sciences of hydraulics, engineering hydrology, structures, soil mechanics and planning methods. From this base a great variety of engineering subjects is derived. The main topics and elements are described in Chapter 4.

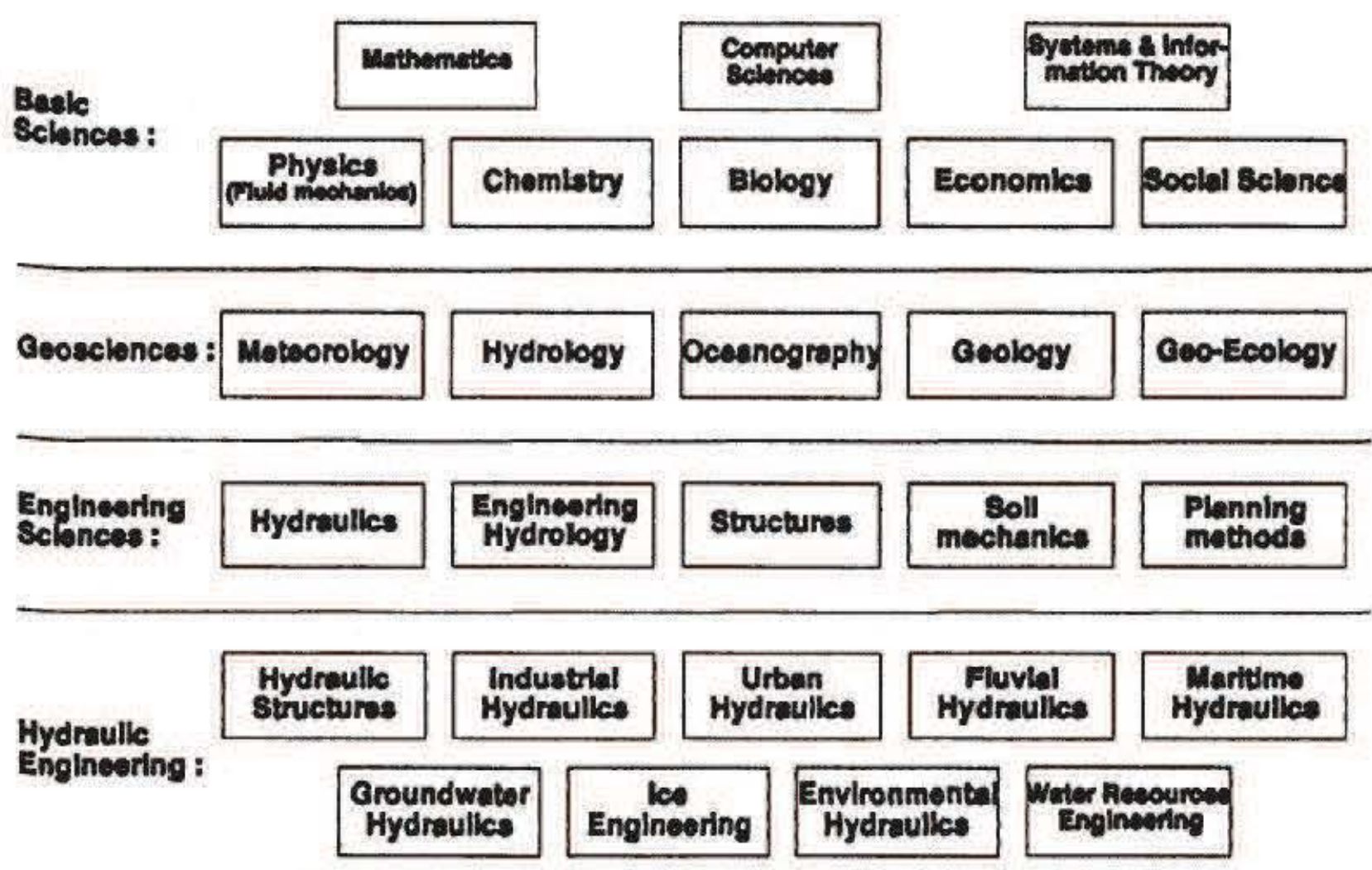

Fig. 1 Scientific basis and topics of hydraulic engineering

\section{Challenges in hydraulic engineering}

\subsection{Present and future tasks for hydraulic engineers}

Hydraulic engineering encompasses a wide variety of tasks in planning, designing, operating and maintaining hydraulic projects and water resources systems [5].

In view of the world's present patterns of development, economic growth and population increase, a conceptual framework has been set by the all-encompassing goal of sustainable develop- 
ment. It is proclaimed that we must meet the needs of the present without compromising the ability of future generations to meet their own needs [1]. However, sustainable development of water resources can certainly not be archieved without constraints, since the ever growing needs for water to support an increasing world population have to be met by the limited natural resources available in an ever sharpening contrast. This poses big challenges to the hydraulic engineering profession.

\subsubsection{Hydraulic structures}

The design of hydraulic structures, which involves the interaction between structure and flow, forms the core of hydraulic engineering. Hydraulic structures for controlling flows are important elements in all of its fields of application. Engineering tasks include the analysis of flows, estimation of hydraulic forces including those due to structural vibrations in addition to considering design aspects such as selection of seals and of proper structural elements based on economic considerations; control and regulating functions, and the impact of the structure upon the water body and the environment.

Probably the most prominent hydraulic structures are dams for water storage. The planning, design, construction and operation of dams are vital parts of a variety of water uses and re-uses by the generation of multipurpose reservoirs: water supply for domestic, irrigation and industrial uses; protection of life and property from flooding; hydro-electric energy generation and storage of large amounts of energy for economic growth; improved navigation by increasing water depth and by creating lakes, and use of reservoirs for fishing and recreation. These uses also involve systems of other structures. For instance, provision of an adequate supply of water for the irrigation of agricultural crops requires structures for diversion by gravity flow or pumping, controlled by gates or valves responding to monitored flow rates.

\subsubsection{Industrial hydraulics}

Industrial hydraulics includes fluid flows under steady and transient conditions in various types of hydromachineries, including turbines, pumps, hydraulic cylinders, valves, pipes and others. More generally, it also includes the design and operation of a wide assortment of equipment such as those to produce gasoline flow in automobile engines and ink flow in computer printers. In many parts of the world, the term "hydraulic engineer" is used to describe those concerned with such fluid motions. Included are the design and manufacture of efficient and durable turbines and the production of large pumping systems to transport different kinds of fluids, including control and monitoring systems.

\subsubsection{Urban hydraulics}

Urban hydraulics includes systems associated with drinking water and industrial water supply, wastewater discharges and the passage of runoff floodwaters through urban areas. Both quantity and quality of water are important. Topics include the hydraulic aspects of development of water supplies from surface and groundwater sources, urban hydrology, low flow and drought analyses, flood forecasting and routing, protection against flooding by structural and non-structural means, real time control of drainage systems, sewer sediments, urban drainage policies, hydraulic elements of treatment plants for both potable water and wastewater, and means for controlling or mitigating industrial water pollution. Operation and maintenance of such systems require techniques for water resources management. 


\subsubsection{Fluvial hydraulics for watersheds and streams}

Fluvial hydraulics consists of the measurement, analysis and management of fluvial processes. Physical processes in streams are determined by the interaction of water and sediments. Hydraulic engineering deals with the estimation and the control of water discharges and of watershed sediment yields; the stream morphology under both natural and modified conditions; the interaction among flow, sediment, and structure (including dams, bridges and bank protection devices). The morphology of a river varies progressively along its course, from the steepest branches of the upland regions down to the flat reaches of the estuary where the river meets the sea. In the middle reach, the sediment sizes in a river are nearly uniform, and the relationship between flows of water and sediment has been thoroughly studied. From the upper reach with a gravel bed to the lower reach with cohesive sediments and saline water, these relationships require further investigation.

\subsubsection{Maritime hydraulics}

Maritime hydraulics covers all aspects of maritime, coastal and estuarine occurrences. It includes coastal morphology, waves, currents, tides, sedimentation and pollution. In working with them, hydraulic engineers deal with wave generation, wave groups, directional seas, wave breaking and longshore currents; water induced forces on structures; transport of bed load and suspended load, cross shore and longshore currents involved in sediment transport and coastal processes; the convection of pollutants by currents, residual drifts, dispersion and diffusion; navigational aspects; the planning, design, operation, and maintenance of harbours, offshore structures, oil pipelines, and coastal protection structures. All such works must be built in accordance with both engineering and environmental criteria.

\subsubsection{Groundwater and porous media hydraulics}

Porous media hydraulics covers groundwater nows in natural media and flows in artificial porous bodies such as drains and sand filters; it includes aspects of both water quantity and water quality. Groundwater systems vary greatly with the geological formation of the aquifer and are characterized by low velocities and extremely long exchange times. Across its open boundaries, groundwater can be polluted by point sources of contaminants or by diffuse sources like agricultural fields. Transport processes take place at the scale of the pore and grain size and are simultaneously affected by larger-scale local heterogeneities of the geological formation as well as by adsorption, chemical reactions and microbiological activities. Hydraulic engineers are involved in groundwater resources management, over-exploitation effects such as land subsidence or saltwater intrusion; groundwater uses; planning, design and operation of water supply systems; and groundwater protection, pollution control and remediation schemes.

\subsubsection{Ice engineering}

The main goals of ice engineering are to protect human life and property against the harmful effects of ice, and to make structural use of ice as feasible. Ice engineering deals with properties of ice; ice formation; ice movements; interaction between ice and flow; thermal regimes of rivers, lakes and oceans; the interaction between ice and structures; the effect of ice on channel morphology; the potential methods to alleviate the dangerous effects of ice; and its potential as structural material. Ice engineering is also involved in the extension of the limits where man can effectively operate and use resources otherwise not or only temporarily accessible. 


\subsubsection{Environmental hydraulics and pollution control}

Environmental hydraulics is concerned with the changes in the environment induced by human activities or by man-made structures The main impacts come from sewage discharges, waste heat discharges and industrial and agricultural pollution sources. Engineering tasks include the design of suitable hydraulic structures (intakes, discharge structures), predictions of transport processes and water quality effects, and strategies for mitigation and prevention. These include the treatment of accidental spills (e.g. oil spills in aquatic environments), wastewater discharges in rivers and coastal zones, contaminant movements, water quality enhancement technologies in rivers and reservoirs, provision for fish passage and spawning, stratification in lakes and oxygenation systems.

\subsubsection{Water resources planning and management}

The complex problems of the sustainable development of water bodies must be addressed in an integrated way. The water resources project and its environment must be viewed as a system containing numerous elements that are related to each other. Therefore, water resources planning and management must be properly based on systems analysis. Thus, risk analysis and the advanced technologies of planning and management are promoted in hydraulic engineering for the design and management of environmentally sound water resources projects.

\subsection{Fields currently evolving}

The encroachment of society and its infrastructure on the environment is receiving increasing attention. Both tangible and intangible impacts of any kind of construction upon the environment is being examined more thoroughly. In the evaluation of a given project, a great deal of effort is required in order to understand the behaviour of natural systems. The definition of criteria for evaluating current and future ecological effects is difficult, and often the goal is "the restoration to natural conditions". Sometimes, a conflict arises between short-term tangible benefits and the long-term intangible welfare of society. Every country must define its goal of sustainable development for improving standards of living and the level of the economy. "Sustainable" is used to describe practices that can continue indefinitely without adverse consequences. Some of the evolving hydraulic issues including several aspects of the proposed new topic "habitat hydraulics" are briefly described in the following sections.

\subsubsection{Impacts of hydraulic structures on the environment}

Since the early 1960's when the impacts of the High Aswan Dam on the Nile River in Egypt became apparent, the ecological and environmental impacts of hydraulic structures have received increasing attention. Now, a comprehensive environmental impact report must be submitted along with the engineering design report for the evaluation of the proposed construction of any large hydraulic project. Often several alternatives are presented and evaluated to make more apparent the tangible and intangible impacts of various approaches. The severe environmental impacts of dams and the corresponding shortage of desirable dam sites are stimulating new design and operation concepts; these include provisions to allow flushing of sediment from the reservoirs in an effort to increase the total time that a reservoir can be used. 


\subsubsection{Stream ecology and river management}

Engineers normally consider the main function of a stream to be the conveyance of water as an important link in the hydrologic cycle. Ecologists look at rivers as an important habitat for plant and animal life aquatic organisms, insects, fish, birds, wildlife, and a wide variety of botanical species. Hydraulic engineers and stream ecologists are learning to conduct research and analyses together. Some critical issues are the enhancement of habitats for fish, wildlife, and flora; the evaluation of instream-flow needs for ecological concerns; the natural trends of streams; effective mitigations for stable streams; approaches to enhance biodiversity; and various water quality issues. Since streams are used for different purposes, they must be managed in complex ways. River management can include flow regulation, flow diversion, structural and non-structural means for flood mitigation, flushing flows for channel maintenance, flow releases for ecological requirements and water quality control. Efforts on renaturalization of river environments also require study of long term stream evolution.

\subsubsection{Wetlands and ecotones}

Wetlands and ecotones are located along streams in and near coastal zones. Due to human developments, enormous amounts of wetland and ecotone that are natural habitats of high biodiversity have been lost. A need for wetland conservation has long been recognized, and some areas are being protected. Recent experience indicates that wetland conservation cannot be left to occur on its own, it needs instead active popular support, especially from the neighboring communities. For each restoration project, hydraulic engineers have joined with ecologists to define ecological criteria and then transfer them into hydraulic criteria so as to achieve predetermined goals. Several alternative plans are proposed as ways of meeting various ecological and hydraulic criteria, and one of them is finally selected as being the most suitable for the environment and for those that will live with it. Currently, there is a move to investigate the possibility of using natural or constructed wetlands to remove excess nutrients such as nitrogen and phosphorous.

\subsubsection{Surface water and groundwater contaminants and water quality}

The pollution of both surface water and groundwater is among the most critical problems facing hydraulic engineers today. Possible sources of pollution include sewage and industrial wastewater discharges, accidental releases of hazardous substances in the environment, like oil spills or other releases of chemicals during transport and handling, agricultural runoffs and deposition of air pollutants. Surface water is polluted by the transport of contaminants in lakes, reservoirs, streams, wetlands, coastal regions, harbors, and the ocean. Groundwater pollution due to industrial and agricultural activities requires enormous restoration efforts. Some current issues in both surface water and groundwater are the transport characteristics of contaminants; the effects of chemical reactions and microbiological processes upon water quality; the development of effective water quality monitoring programs for specific sites; conjunctive use of surface water and groundwater; water quality control; and reduction of contaminant inputs from industrial and agricultural sources.

\subsubsection{Alternative and renewable energy sources}

In view of the limitations on the world's supply of fossil fuels and because of the ecological, political and economic constraints on conventional energy production, alternative energy sources such as solar or geothermal energy and wind, waves and tides have been evaluated. The economic value of wave and tidal energy is still uncertain. Geothermal energy based on hot water and hot 
air is worth developing, but only if geological conditions are favourable. Hydraulic engineers are challenged by these developments, and at the same time they are traditionally involved in the use of such conventional energy sources as hydropower, nuclear power, fossil fuels and coal.

Water power traditionally is the most prominent renewable energy source. Due to the ecological impacts and the limited number of new dam sites, the construction of hydropower installations in many developed countries has been significantly retarded in recent years. Nonetheless, its importance in developing countries is still growing. Furthermore, developments like pumped storage schemes enlarge the possibilities offered by hydropower. Globally, the available potential of water power offers many promising perspectives, provided that the hydraulic schemes involved are properly planned and operated.

\subsubsection{Natural disaster reduction and mitigation}

Water-related natural disasters such as floods, tsunamis, typhoons and hurricanes, landslides or droughts cause the loss of many lifes and huge amounts of damages each year. In the world wide effort to curb the losses and damages and to mitigate the effects of such extreme events, hydraulic engineering has a major role to play.

\subsubsection{Global climatic changes}

The possibility of global climate change due to the greenhouse effect is currently receiving much attention. Global warming could cause the sea level to rise, a change that would alter coastal processes and increase the need for shore protection. There is also growing concern that even minor climatic changes may have significant effects on the hydrological cycle and the occurrence of extreme events, and these would severely affect the design and performance of hydraulic schemes.

\section{Educational goals and requirements}

\subsection{Educational objectives for hydraulic engineering}

Because of the wide variety of tasks that fall within the interrelated fields of hydraulic engineering, water resources planning and water systems management, no single curriculum can include all that may be required. Formal education (in both skills and tools) must therefore include curricula that are aimed at a variety of goals. The need for well trained professionals is growing rapidly with the ever increasing demands on the world's supply of water. Also, because these demands change 2 the systems evolve, a comprehensive system of continuing education for lifelong learning is required to deepen, to widen and to extend the formal education offered by the universi-. ties.

University curricula in hydraulic engineering vary greatly from country to country. They are influenced by national physiography, culture, economy and the educational traditions that have evolved. Nonetheless, the engineers that are graduated have learned how to face much the same kinds of challenges and to do so in a variety of settings. Their careers, regardless of the tradition from which they come, may encompass tasks in research, planning, administration, construction, maintenance and operation, for the wide variety of structures and systems that are needed.

The challenge to educators is to help build the human resources to cope with a broad range of water-related tasks [8]. Capacity building must supply persons to work at all levels in water 
systems. It must encompass the training for qualifications ranging from technicians to administrators. Managers must oversee large-scale operations; service personnel are required for collecting and applying information, operating and maintaining hydraulic structures and managing various aspects of systems that can be quite extensive.

The philosophy of formal educational systems to supply these specialists should be defined in the light of what hydraulic engineering practice requires of a university graduate. These needs define which elements should be contained in basic engineering training, which levels are appropriate for professional engineers and which are suited to postgraduate education.

In view of the limited scope of educational programs, one of the essential questions concerns the goal of formal education: whether the emphasis is placed on a generalist with a broad approach and background or on a specialist with a more detailed technical and engineering background. Should the hydraulic engineer be a specialist in the traditional sense (although with an awareness of environmental, economic and other aspects) or one oriented toward water resources, more as a generalist, with training in economics, ecology, regional planning, and the like?

Developments in many parts of the world indicate that, in addition to the "classical" hydraulic engineer, a new type of more broadly based hydraulic engineer is evolving: one who is devoted to water resources and environmental planning and who would incorporate understanding of the environmental system, economical aspects and planning methods in to his basic training in place of some of the structural engineering courses. These can be seen as two distinct types of education. One can draw a parallel with the developments of teaching structural engineering, which has brought about the very distinct basic courses for civil engineering design and construction on the one hand and for architecture and city planning on the other.

A closely related requirement is an adequate training of environmental engineers, ecologists and infrastructure planners, who have to be informed about the role of hydraulics in water systems but whose specialization is in their specific related fields. These professional groups and hydraulic engineers must devise ways of working together productively.

\subsection{Principal topics in hydraulic engineering}

The following subsections indicate both the present state of the basic courses in hydraulic engineering and developments that are taking place now or will do so in the near future. To some extent the subject is in a state of flux; new courses and methods of learning are evolving, and these use more visual and computer-based teaching aids.

\subsubsection{Hydraulics}

Hydraulics may be defined as the application of the principles of fluid mechanics to the solution of engineering tasks involving the movement of water and the transport of water-borne substances. This process includes the collection, usage and redistribution of surface, ground and seawater in both space and time and the determination of forces exerted by the water flow. Traditionally, hydraulics is based on simplifications of fluid mechanics through dimensionless representations and the use of both empirical coefficients and accumulated experience. The possibilities offered by the computer have broadened the approach to modern hydraulics. The traditional approach, based on hydraulic models studies and semi-empirical formulas representing onedimensional approximations, has been gradually extended to include numerical methods based 
on solving directly the partial differential equations of fluid mechanics. Applications include a broad spectrum of natural and constructed water systems as well as techniques for solving water quality problems with the inclusion of morphological, chemical and biological processes.

\subsubsection{Engineering hydrology}

Hydrology in its broad sense has emerged during the last decades as a fundamental natural science whose applications extend into the geosciences and into many engineering fields [6]. Hydrology is concerned with water in the hydrologic cycle of the earth, and it includes its interactions with the atmosphere, oceans and glaciers. Its central concern is with the water and the land environment, but it also embraces the processes of evaporation, condensation, precipitation, advection, freezing and thawing. Moreover, the hydrologic cycle determines the transport and deposition of water-borne substances, and the water-related effects on vegetative life.

Originally approached by hydraulic engineers to obtain design information like extreme discharges, extreme flood waves or extreme low flows, hydrology developed a tradition of its own. The complete hydrological cycle has assumed a new significance to engineering more recent applications treat rainfall in distribution and magnitude as input into models of erosion processes; evaporation as a part of irrigation or of water losses from reservoirs and rivers; runoff as inflow into reservoirs, replenishment of water supplies and cause of floods. Quite obviously many of the hydrological inputs that the engineer needs today for his designs had not even been formulated prior to 1950 . In addition, the work that has to be done in countries with inadequate hydrological records requires that hydrology be seen in its climatic context: the hydrological conditions of tropical and arid regions, for example, differ greatly from each other and from the hydrology of moderate climates.

Many universities have responded to the broadening scope of hydrology by establishing curricula leading to a degree in hydrology. UNESCO has recently elaborated curricula and syllabi for hydrology in university education [4] for different streams of study.

\subsubsection{Hydraulic structures}

A key element in hydraulic engineering concerns hydraulic structures. Their hydraulic function, design and structural implementation are the core of the discipline; so are the ways in which the water regime and the flow pattern are affected by the structure and how the environment responds to the resulting changes. The design of such structures must include not only considerations of reliability and economy of construction, maintenance and eventually removal, but also the various impacts upon the water body with all their consequences to the flow and the quality of the water. Considerations of all relevant aspects of sustainable development are also essential in the planning and design of hydraulic structures.

The structural elements of such projects comprise an important part of civil engineering. Structural analysis, materials science and the technology of structures are core subjects in hydraulic engineering. For most applications, the types of structures and their design have evolved over many decades, and only for extremely large structures, such as high dams or navigation locks with high lifts, do engineers face problems which require new solutions. New challenges come from applying new construction technologies and from the application of value engineering and probabilistic design to provide economically balanced solutions. 
As the most prominent examples of hydraulic structures for such purposes as water storage, hydropower, flow mitigation or water supply, over 200 dams higher than $15 \mathrm{~m}$ are completed each year. The world's 36,000 dams store about $6000 \mathrm{~km}^{3}$ of water. Dams are indispensable structures for regional development, and recent concerns have been strongly oriented towards ways that make them more compatible with local conditions: to design them so as to cause as little disruption of the social and natural conditions as feasible. Environmental, social, safety, and cultural aspects of dams and reservoirs are now addressed in the early stages of planning. The negative consequences of dam construction are mostly local, and in most cases they can be counterbalanced by sound planning, adequate design and appropriate measures to control adverse effects.

\subsubsection{Soil mechanics}

Soil mechanics forms the basis of geotechnical engineering as a key element of all civil engineering structures. Particularly for large structures like those encountered in hydraulic engineering, soil mechanics is of paramount importance. A large part of major structural failures are traceable to foundation problems. Furthermore, the structure of natural soils and their material properties are important aspects of natural water systems. Interactions between fluid flows and soils include effects on the stability of structures, erosion processes by wind and water flows, sediment transport, sedimentation and seepage effects, groundwater flows, land subsidence, and resulting changes in the natural flow and transport systems.

\subsubsection{Planning of water resources projects}

Hydraulic engineers need a sound basis in planning methods. The planning and operation of major water resources systems is possible by means of tools originally developed for industrial processes and economic systems. Optimization techniques such as linear and dynamic programming and mathematical optimization methods ranging from simple gradients to neural systems are widely applied in water resources studies. For example, the local interaction of water resources systems with the environment can be described by conceptual and mathematical models that are comparatively simple. Also, engineers have been successful in creating sectorial systems serving a single dominant purpose, such as water supply, hydropower or irrigation. Traditional knowledge in these fields forms the basis for simulation techniques commonly used in water resources engineering.

Simulation in water resources engineering is understood to mean the assessment of the dynamic performance of an element of a water resources system. The important characteristic of simulation is that calculations are done in the time domain by representing the system element in a model: in this process the input is a set of time functions that represents a natural process, such as a sequence of monthly discharges or of conjectured future water demands.

Water resources planning is aimed at gaining an understanding of its multiobjective and multipurpose aspects in which conflicting objectives must be evaluated and counterbalanced. Economic analysis is required to evaluate costs, and management skills and planning methods are applied to coordinate various efforts. Since the major climatic and flow parameters vary greatly, probabilistic and risk analyses are employed as appropriate. These techniques are also important because of the uncertainties involved in future projections. The current developments of remote sensing, satellite images and Geographical Information Systems (GIS) may serve as powerful tools in the future. 


\subsection{Major subject areas in hydraulic engineering}

Each student should take courses in several specialized topics in accordance with his career interests. Some major applied topics in hydraulic engineering, from which the student can select only a few, are the fields listed in Figure 1. These suggest the following subject areas:

- Design and operation of hydraulic structures

- Energy systems conversion, transport, storage in reservoirs, hydropower

- Fluvial hydraulis, geomorphology and related geosciences

- Oceanography waves, currents, shore erosion and protection

- Climatology, and advanced topics in hydrology

- Agricultural engineering, irrigation and drainage

- Hydrogeology and groundwater systems

- Water quality, aquatic chemistry, and microbiology (pollution control)

- Introduction to ecology

- Statistical and stochastic methods

- Systems analysis and decision making

- Cultural, social and legal aspects of planning and management

- International aspects and special concerns of third-world areas

\subsection{Engineering skills and procedures}

Education in hydraulic engineering should include the confrontation with real world design projects as well as a variety of experiences outside the classroom:

- Essential to the learning of fluid mechanics is some experience in the laboratory to familiarize the student with fluid properties and flow phenomena and to confront him with hands-on experiments, performance of measurements and processing of experimental data. A logical extension of this part of learning is a course on hydraulic modelling, similarity considerations and hydraulic laboratory practice.

- Equally important is the need to confront students with the collection of hydrological field data, including an introduction to the instruments used. This should give them a feeling for the reliability and degree of accuracy of such data, for the time variability of all hydrological processes and for their spatial variability.

- Field trips to hydraulic structures either under construction or in operation allow students to learn about the reality of such structures and how they function. Students can also learn from professional engineers how public opinion enters into planning and how it can be accommodated. Such experience helps to illustrate how the theories taught in the classroom work out in practice and to indicate some of the difficulties encountered.

- These developments in field and laboratory techniques are complemented by the emerging field of hydroinformatics, which encompasses the applications of information technology and the use of computers. It includes the use of Geographical Information Systems (GIS), other information systems and decision support systems to provide the desired level of aggregation of many interrelated aspects of the water system; systems engineering to design integrated systems; and integration of numerical modelling into information systems. 
- Computer aided design (CAD) must be developed for use specifically in hydraulic engineering. The advantages of illustrating physical principles while showing how to work with them (in interactive programs) will clearly establish the computer in the curriculum of the future. A tremendous advantage of interactive computers lies in the teaching of all kinds of techniques used for data analysis from the analysis of experimental data by means of dimensionless numbers to more elaborate investigations in multivariate statistics. Also, computer experiments can be performed in classrooms in them the computer takes over the role of the laboratory flume or of a set of representative field data, and the student experiments with inputs and observes the results on the screen of a personal computer. Comparisons of physical experiments in a flume with numerical calculations also enables the student to learn about the validity of the simplifying assumptions that are inherent in all numerical models.

\subsection{Professional preparation}

Hydraulic engineets can have careers of several types: in the construction or power industry, in water supply, in water resources management (public service), and in research and/or educational institutions. Often engineers begin their work in a relatively narrow branch of their engineering field, then gradually broaden their field of interest to become associated with a variety of disciplines.

Skills that should be acquired during preparation for a professional career in hydraulic engineering include:

- Communication skills

- Group planning methods

- Working with concepts and information without complete and specialized knowledge

- Developing awareness of widely different points of view and methods for their reconciliation (general public, administrators, planners, contractors, managers)

- Management skills and training for informal leadership

Acquisition of such important skills requires some guided experience with real-world projects. The inevitable time constraints on formal university education mean that only some aspects can be treated thoroughly and consequently others are left for study in some form of continuing education.

Hydraulic engineers now have to include the analysis of the environmental impacts of a complex project through an approach that coordinates their efforts with those of other disciplines. Interdisciplinary team work and management are receiving ever increasing attention, and the selection of the team leader is often based on overall knowledge of the problem. The appropriate amount of training in different disciplines for hydraulic engineers depends on the preference of each individual, but the need may arise to specify a minimum amount of such training. Some universities in the United States are discussing the requisite courses in biology, chemistry or ecology for hydraulic engineering students.

\subsection{Continuing education}

Continuing education is important in career learning, and it is likely to become more so. It can supplement formal education by seminars, short courses or computer-aided learning technolo- 
gies and help engineers to qualify for the evolving needs of their profession and of society.

Needs for continuing education differ widely from region to region; they depend on the nature of prior education, professional requirements in a country and the type of projects common to a specific region. They also depend upon the type of career an engineer undertakes. After an education in hydraulic engineering, an engineer can use continuing education to deepen knowledge in a narrow field of specialization, to broaden knowledge in relevant subjects or to supplement managerial skills. The flexibility inherent in continuing education allows programs to be directed towards selected targets:

- Career enhancement: teaching systems engineering and introducing neighbouring subjects into integrated career planning, thus broadening qualifications for leadership and management. Water management is a part of environmental management. Hydraulic engineers are responsible for public works and for water resources systems, including their management and operation. Their work must encompass not only the technical and environmental elements inside the system, but also the impacts it may have both on more global systems and on the social system beyond the project.

- Specialized topics for those whose work takes them into adjacent fields: examples are environmental engineering, water chemistry, infrastructure planning, economics, agriculture, ecology and biology.

- Training for higher qualification in the use of methods and tools: these include numerical modelling, hydroinformatics, field observation techniques, laboratory techniques and statistical methods.

- Specialized training for research students. Unlike the Anglo-Saxon countries, many parts of the world do not have formal graduate programs at their universities. In these countries, continuing education by means of a suitable system of short courses is a way to formalize and improve the qualifications of advanced students.

\subsection{Global aspects}

A key factor in world development is the availability and wise usage of water as a crucial natural resource that is abundant in some parts of the world and quite scarce in others. The hydraulic engineer should be made aware of the problems which are increasingly threatening:

- Increases in the demand for water as the world population increases,

- International conflicts that may arise over the usage of rivers common to two or more countries,

- Rapid industrialisation, which will also increase water consumption,

- Intensive agriculture, including over-exploitation of groundwater reserves,

- Pollution and deterioration of water quality of both surface waters and groundwater as a result of growing human settlements, industrial wastes and agricultural activities,

- Global climate changes that may have drastic impacts upon the global water cycle.

Capacity building in water resources engineering in all parts of the world is of paramount importance in striving towards sustainable development of the global water resources. Enormous international efforts will be required if available water resources are to be used wisely and effecti- 
vely to overcome water shortages in many parts of the world, to avoid over-exploitation and to mitigate flood damages. All such tasks will require an ever increasing number of professionals of ever higher levels of competence.

Global needs that require specialized education have long been recognized by UNESCO and by water-related international organizations such as IAHR. Additional educational efforts are required on all levels of education and training in the various parts of hydraulic engineering. New concepts in both research and management need to be incorporated promptly into established programs. UNESCO has been sponsoring international courses in hydrology and water resources for 25 years. IAHR, as a world-wide non governmental association of professionals in the field of hydraulics and hydraulic engineering, provides a well functioning network for the implementation and rapid dissemination of new practices via continuing education on an international scale. It is contributing to information exchange towards these goals through publications, international courses, seminars and conferences.

Finally, a broader public understanding of the issues, strategies and techniques involved in hydraulic engineering should be promoted. General objectives are:

- to increase public awareness of the importance of sustaining the environment,

- to improve knowledge of the water related sciences at all levels,

- to facilitate the transfer of results from research and technological developments to the professionals involved in integrated water resources development and management,

- to foster cooperation among nations and within regions to solve conflicts related to development of shared water resources.

\section{Conclusions}

Hydraulic engineering is a discipline with a tradition that goes back to the dawn of civilization. Over millennia its engineers have developed the means to solve many practical problems, and it continues to offer many challenging tasks and career opportunities. Education in hydraulic engineering must convey the well established state of the art as well as the most recent methods and their balanced use:

1. The educational background of a hydraulic engineer is based on science, particularly fluid mechanics and geoscience, and on such applied topics as hydraulic structures and engineering hydrology. It also includes coordinated sets of electives suitable for the intended field and degree of specialisation.

2. Learning in the classroom should be complemented by laboratory exercises, computer experiments, field trips and project case studies.

3. Hydraulic engineering should be taught in a broad context of the natural and social environment and must enhance the engineer's sense of responsibility for sustainable water development within environmental and societal limitations.

The growing demand for water to fulfill the many needs of a steadily growing population challenges educators to diversify their offerings and to produce skilled engineers and technicians in greater numbers. Furthermore, the broadening of the scope for water projects in the latter part of the current century has dramatically influenced the practice of hydraulic engineering:

4. In recent decades, hydraulic engineering has broadened to become increasingly involved with water quality and a variety of related environmental issues. Hydraulics is intrinsically involved 
because it provides the physical basis for hydraulic transport processes of sediment, dissolved matter, oxygen, nutrients, heat and contaminants and these are the key ingredients of water quality modelling. The scope of engineering tasks is further broadened by the new challenges posed by the need for sustainable development and by the threat of global changes.

5. Multi-objective planning of complex projects requires new methodologies and some changes in the way engineering is practiced. Alternative plans, in order to assess uncertainties and intangible impacts (non-quantifiable objectives), are often needed. Such formulations and their utilization in planning require special learning processes that are dependent on systems analysis, uncertainty concepts and stochastics.

6. Because the primary goal of most projects involves the movement of water or other waterrelated processes, the hydraulic engineer will normally be the one to coordinate multidisciplinary efforts. Preparation for this task should include some training in leadership and the development of a genuine sensitivity to the viewpoints and needs of other specialists and other cultures. The ability to communicate, both orally and in writing, is implicit in this activity. This includes preparation for efficient communication in the public domain, particularly in the form of well balanced presentations of the objectives of projects in their environmental and social contexts.

Implicit in these developments is the need for many practicing hydraulic engineers to be both specialists and generalists. This need must be reflected in the requisite educational systems and programs:

7. The wide variety of water needs, resources and cultures to be served requires hydraulic engineers to interact with natural and social scientists from such fields as geology, geography, economics, fishery biology, ecology and sociology. To facilitate this process, educational organizations must extend their offerings to include

- new courses that will assist in the integration of these related fields into hydraulic engineering curricula,

- special courses that will present the elements of hydraulics to students in some of these other disciplines,

- introductory courses preparing for the unusual requirements of group activities and some participation in such team activities.

8. Both current programs and new ones that will surely emerge would benefit from educational guidelines on the topics that should be included and the depth or quantity required. The requisite manpower to be trained includes a range of levels and a variety of disciplines. Some of the major needs for new programs are in the less developed world where water problems are often severe and trained manpower is often lacking.

9. Limitations on what and how much can be done through formal education clearly show the need for major contributions through continuing education. Such programs can be designed and modified to meet changing requirements. Frequently they will involve strong components of internationalism, both in the learning program and in the cadres involved in the process.

10. Hydraulic engineering has important international aspects in that

- most large new projects will be in the less developed parts of the world; 
- many of them involve the interests of more than one country because most of the world's larger rivers are international;

- the variety of cultures that must work together requries a comprehensive and two-way interchange of information, value assessment and procedural matters.

As a consequence, international learning and information transfer should be strongly advanced. Since direct cooperation of specialists is the most efficient way to transfer knowledge, the mobility of professionals, teachers. researchers and students between nations and regions should be stimulated.

Several of the proposed activities clearly benefit from the support of international organizations like IAHR. In response to these important tasks, IAHR has established a Committee on Education and Training that addresses particularly to the topics of the foregoing conclusions related to educational guidelines, continuing education, and mobility of professionals.

\section{References}

1. Brundtland, Gro H. et al.: "Our common future. Report of the World Commission on Environment and Development"; Oxford University Press, 1987

2. Davis, Calvin V.: "Handbook of applied hydraulics", McGraw-Hill, New York, 1952

3. Jordaan, J., E.J. Plate, J.E. Prins, J. Veltrop: "Waterin our Common Future: A Research Agenda for Sustainable Development of Water Resources", UNESCO Publication, Paris, 1993

4. Maniak, U. (Ed.): "Curricula and syllabi for hydrology in university education", UNESCO, IHP-IV Project E-2.1, Technical Documents in Hydrology (113 p), Paris, 1993

5. Müller, Andreas (ed.): "IAHR looking into sustainable development Research agenda and future topics of concern", IAHR Publication, Delft 1993

6. Nash, J.E., P.S. Eagleson, J.R. Philip, W.H. van der Molen: "The education of hydrologists", Hydrological Sciences Journal, Vol. 35, No 6, pp. 597-607, Dec. 1990

7. Plate, E.J.: "Contributi degli esperti stranieri", Idrotecnica, No. 6, pp. 381411,1985

8. Raynal, J.A. (Ed.): "Hydrology and water resources education, training and management", Water Resources Publications, Littleton, Col. USA, 1992

9. Rouse, Hunter (ed.): "Engineering hydraulics", John Wiley and Sons; New York, 1950

10. Schleicher, Ferdinand (Hrsg.): "Taschenbuch für Bauingenieure”, Springer Verlag, Berlin, 1942 